\title{
A influência do programa Bolsa Família nas taxas de emprego nos municípios brasileiros
}

\author{
The influence of Bolsa Família program on employment rates in Brazilian \\ municipalities
}

\author{
Leonardo de Queiroz Cobuccio', Andrea Rodrigues FerroII
}

\begin{abstract}
RESUMO
O Bolsa Família é um programa de transferência condicionada de renda que tem como propósito erradicar a pobreza e promover um maior acesso à saúde e educação. Dados os seus benefícios e condicionalidades, o programa gera diversos impactos na sociedade. Este trabalho tem como objetivo analisar o efeito do Bolsa Família sobre as taxas de emprego, mortalidade e trabalho infantil, renda domiciliar e proporção de pobreza nos municípios brasileiros. Para tanto, foram utilizados dados em painel para os anos de 2000 e 2010, extraídos do Ipeadata e do DataSUS. Como resultado desta pesquisa obteve-se resultados estatisticamente significativos e com o sinal esperado entre o PBF e as taxas de emprego, mortalidade infantil e renda domiciliar, apesar de pequenos.
\end{abstract}

Palavras-chave: Bolsa família; Desemprego; Trabalho infantil

\begin{abstract}
The Bolsa Família is a conditional cash transfer program that aims to eradicate poverty and promote greater access to health and education. Given their benefits and conditionalities, the program generates several impacts on society. This work aims to analyze the effects of Bolsa Família on the employment rates, child mortality and labor, household income and poverty ratio in Brazilian municipalities. For that, panel data were used for the years of 2000 and 2010, extracted from Ipeadata and DataSUS. We obtained statistically significant results between the PBF and the employment rates, child mortality and household income, in the expected directions, though small.
\end{abstract}

Keywords: Bolsa família; Unemployment; Child labor 


\section{INTRODUÇÃO}

O Brasil é considerado um país de elevada desigualdade social, estando sempre presente entre os países com pior distribuição de renda no mundo. Em 2015, por exemplo, o índice de Gini brasileiro era 0,51, próximo a de países como Colômbia e Panamá (THE WORLD BANK, 2016). Uma das possíveis soluções para a desigualdade é a transferência de renda para os mais pobres. Para tanto, têm sido criados programas sociais de transferência de renda em todo o mundo, sendo que no Brasil o principal deles é o programa Bolsa Família (PBF).

O PBF foi criado no ano de 2003 pela Medida Provisória no 132 a partir da junção de outros programas sociais já existentes: Bolsa Escola, Bolsa Alimentação, Auxílio-Gás e Cartão Alimentação. Os beneficiários desse projeto são as famílias consideradas pobres e extremamente pobres, com crianças e adolescentes de 0 a 15 anos e jovens de 16 a 17 anos. Segundo os critérios do programa, são consideradas famílias pobres aquelas que apresentam, em valores de 2018, renda mensal entre $R \$ 89,01$ e $R \$ 178,00$ e extremamente pobres aquelas que apresentam renda mensal menor que R\$89,00 (MDS, 2018).

Dez anos após sua criação, em 2013 o PBF já atendia cerca de 13,8 milhões de famílias em todo o Brasil e possuía um sólido instrumento de identificação socioeconômica, o Cadastro Único. O programa atuava, e ainda atua, com base nas necessidades materiais imediatas de acordo com as características de cada família beneficiada.

Para o recebimento do benefício é necessário o cumprimento de algumas condicionalidades, cuja intenção é promover melhores condições de saúde e educação dos beneficiários nos médio e longo prazos. Em relação à educação, estipula-se uma frequência mínima às aulas de $85 \%$ no ensino fundamental e de $75 \%$ no ensino médio; enquanto para a área de saúde são exigidos exames pré-natais para gestantes, acompanhamento pediátrico para crianças de até seis anos e atualização do calendário de vacinas (CAMELO; TAVARES; SAIANI, 2009).

Entretanto, a transferência de renda promovida pelo Bolsa Família divide a opinião pública sobre os seus efeitos na oferta de mão de obra dos beneficiários. Indivíduos contrários ao programa argumentam que o auxílio monetário a essas famílias estimula a permanência dos beneficiários no desemprego, afirmando que o dinheiro recebido serve como um incentivo ao comodismo de "lucrar sem esforço".

É a partir dessa discussão que este artigo busca responder: afinal, o Bolsa Família influencia as taxas de desemprego? O Bolsa Família atua como um programa que incentiva o comodismo ou como um programa que incentiva a procura de emprego pelos beneficiários? Ou ainda, é um programa que não possui efeitos relevantes sobre as taxas de emprego?

O principal objetivo deste artigo é investigar a relação entre o PBF e as taxas de emprego nos municípios brasileiros. No entanto, também foram realizadas análises sobre 0 efeito do programa na saúde, mortalidade infantil, e na renda, pobreza e desigualdade, utilizando medidas agregadas por município.

Utilizando um painel de municípios brasileiros entre 2000 e 2010, investiga-se o impacto do PBF sobre as taxas de emprego, proporção de óbitos infantis evitáveis e proporção de pobres, dentre outras medidas. 


\section{O PROGRAMA BOLSA FAMÍLIA E SEUS EFEITOS}

Em relação à pobreza e à desigualdade, Soares e Sátyro (2009) mostram que houve uma queda das taxas de pobreza e de extrema pobreza e uma redução significativa do índice de Gini, ambas associadas à implantação do programa. A análise do coeficiente de Gini, dividida em dois períodos, evidencia a relevância do programa sobre a desigualdade no país. De 1995 a 2004, o coeficiente cai cerca de 3 pontos e representa um bom ritmo de queda, uma vez que ocorre após o ano de 2001. A análise ainda revela que o Bolsa Família contribuiu com $19 \%$ dessa queda, mesmo sendo responsável por apenas 0,5\% das rendas das famílias. No segundo período, de 2004 a 2006, o coeficiente cai cerca de 1 ponto e representa um ritmo razoável, mais lento quando comparado ao anterior. Entretanto, agora o PBF é responsável por $21 \%$ da nova queda, devido à progressividade dos benefícios.

Soares et.al. (2010), por sua vez, estudam o comportamento do coeficiente de Gini no período de uma década, entre o ano de 1999 e o ano de 2009. O resultado obtido é de queda do índice, de 59,2 para 54, sendo o Bolsa Família responsável por 15\% dessa queda, mesmo representando $0,7 \%$ das rendas familiares.

Quanto à redução da pobreza, uma comparação entre as famílias com e sem Bolsa Família para analisar reduções, hiato e severidade da pobreza, usando dados da Pesquisa Nacional por Amostra de Domicílios (PNAD) do ano de 2006, mostrou que a porcentagem de pessoas pobres não sofreu uma redução muito relevante, sendo de 1,64 pontos percentuais, o que equivale a apenas $8 \%$. Segundo os autores, esse resultado ocorre porque a linha de pobreza configura valores abaixo de $\mathrm{R} \$ 120,00$ e, como os benefícios do PBF são substancialmente menores do que esse valor, o impacto acaba não sendo muito expressivo. Já os impactos sobre o hiato de pobreza e a severidade da pobreza são maiores e mais relevantes: o hiato apresenta uma redução de $18 \%$ e a severidade é reduzida em 22\% (SOARES; SÁTYRO, 2009).

Analisando a pobreza, e considerando a linha de pobreza quando a renda estava abaixo de $R \$ 100,00$, e a linha de pobreza extrema, quando a renda abaixo de $R \$ 50,00$, com dados da PNAD de 1998 a 2010, Sorares et. al. (2010) observam uma queda mais acentuada começando no período entre os anos de 2003 e 2005, exatamente o de unificação e dos programas de transferência de renda no PBF e de expansão da sua cobertura. De 2004 a 2009, a pobreza reduziu quase 12 pontos percentuais: de 26\% para $14 \%$, representando uma redução de quase 50\%; sendo o Bolsa Família responsável por aproximadamente $16 \%$ dessa queda. Já a pobreza extrema reduziu mais de 5 pontos percentuais: de $10 \%$ para $4,8 \%$, representando uma redução de mais de $50 \%$; sendo os benefícios do Bolsa Família responsáveis por quase um terço dessa queda.

Ao analisar a focalização do programa, Tavares et.al. (2008) encontraram dados mais significativos e expressivos do Bolsa Família sobre a extrema pobreza do que sobre a pobreza. Segundo Soares, et al. (2010, p.50), o PBF parece chegar em um momento de saturação no que diz respeito ao seu impacto na redução da pobreza, sendo necessário um novo arranjo para o programa, com benefício e número de beneficiários maiores. No entanto, mesmo sem as mudanças sugeridas, o programa continua essencial para a manutenção dos efeitos das suas contribuições passadas.

A análise dos impactos do Bolsa Família sobre a saúde tem resultados divergentes. Entretanto quando o tema é mortalidade infantil, os trabalhos apontam para efeitos positivos ou não significativos.

Utilizando dados de 2004 a 2009 em 5507 municípios brasileiros, Campelo e Neri (2003) mostram que o impacto do Bolsa Família sobre as taxas de mortalidade infantil é 
negativo e estatisticamente significativo. Os autores argumentam que um efeito causal desse impacto é a redução das taxas de hospitalização em menores de cinco anos e a elevação das consultas pré-natais e da cobertura de vacinas.

Também com o objetivo de verificar os efeitos do PBF sobre a mortalidade infantil, o método de dados em painel foi utilizado para os anos de 2000 e 2010 por Oliveira (2014). Foi encontrado, assim como no trabalho de Campelo e Neri (2013), resultados estatisticamente significativos entre o programa e as taxas de mortalidade infantil, representando relação negativa para a mortalidade de ambos os sexos.

Apesar dos resultados positivos encontrados nos estudos mencionados, em 2009 foi constatado impacto estatisticamente não significativo do Bolsa Família sobre as taxas de mortalidade infantil, apesar de constatar efeito positivo e significativo do PBF para casos de crianças com sobrepeso, uma vez que possibilita uma maior variabilidade alimentar, com a transferência condicionada de renda, e algumas obrigações relacionadas a saúde infantil, como o acompanhamento pediátrico de crianças até 6 anos (CAMELO; TAVARES; SAIANI, 2009).

O ponto principal deste artigo é a avaliação da relação que existe entre o PBF e as taxas de emprego nos municípios do Brasil. Nos trabalhos revisados, os impactos do Bolsa Família sobre o emprego são positivos e estatisticamente significativos ou nulos, o que reforça a ideia de que o programa não provoca desestímulo do trabalho.

Muitas críticas ao programa estão relacionadas ao chamado "efeito preguiça", que consiste numa espécie de acomodação dos beneficiários, ou desincentivo ao trabalho, causada pela transferência de renda realizada pelo Bolsa Família. Uma análise teórica macroeconômica, como sugerida no trabalho de Soares e Sátyro (2009), expõe dois pontos de vista: o primeiro, do efeito renda, defende que o aumento da renda por conta da transferência condicionada muda os preços relativos das famílias, torna os bens mais acessíveis, e pode diminuir a oferta de trabalho; já o segundo defende que essa renda condicionada pode cobrir os custos de uma procura mais intensa por um novo emprego. Os resultados encontrados não corroboram os argumentos de que o programa proporciona um "efeito preguiça", ou efeito renda.

Ao analisar a taxa de participação e o número médio de horas trabalhadas em nível municipal de homens e mulheres adultos através de dados da PNAD coletados durante o período de 2001 a 2005, foram encontrados impactos do PBF, em sua maioria, não significativos. Para o sexo feminino, o impacto sobre a taxa de participação não foi significativo; já para as horas trabalhadas, o efeito do Bolsa Família foi negativo, entretanto foi considerado um impacto pequeno e estatisticamente não significativo. Os resultados para o sexo masculino foram bastante semelhantes aos das mulheres, apresentando efeito positivo sobre a taxa de participação, entretanto pequeno em magnitude; já para as horas trabalhadas, o efeito do PBF foi não estatisticamente significativo (FOGUEL; BARROS, 2010).

Também analisando dados sobre a força de trabalho adulta, em Teixeira (2008) estimou a sensibilidade de homens e mulheres às intensidades do choque orçamentário que o Bolsa Família proporciona, no que tange a oferta de horas de trabalho. Alguns dos resultados obtidos apontaram para efeitos pequenos e estatisticamente não significativos para as horas trabalhadas de homens autônomos e nenhum efeito para os homens no setor formal; já os efeitos para o sexo feminino são maiores, tanto para mulheres autônomas quanto para mulheres no setor formal.

Soares, Ribas e Osório (2010) utilizaram de dados da Avaliação de Impacto do Programa Bolsa Família (AIBF) para comparar as taxas de participação no mercado de 
trabalho entre beneficiários do Bolsa Família e não beneficiários. A análise constatou que a participação no mercado de trabalho de homens adultos beneficiários foi de 2,6 pontos percentuais maior do que a de homens não beneficiários; já em relação as mulheres, relatou-se 4,3 pontos percentuais a mais de mulheres beneficiárias em relação a não beneficiárias no mercado de trabalho.

Também foi analisado o impacto do Bolsa Família sobre a oferta de trabalho das mães beneficiárias. Os resultados encontrados apontaram para uma elevação da participação das mães no mercado de trabalho, assim como as horas trabalhadas. A condicionalidade do programa de obrigação de frequentar as escolas faz com que seus filhos passem mais tempo nas escolas, representando um maior tempo disponível de trabalho para as mães. Existe também a possibilidade das crianças que poderiam ser sinônimo de renda para a família, e que passam agora a representar uma "perda" na contribuição da renda familiar com o aumento de sua frequência escolar, assim as mães se encontram obrigadas a aumentar sua força de trabalho para compensar essa redução nos ganhos da família (TAVARES, 2010).

Ferro, Kassouf e Levison (2010) apresentam resultados parecidos com os de Tavares (2010) ao demonstrar a relação entre a força de trabalho infantil e a participação no mercado de trabalho dos pais de famílias beneficiárias do PBF. As autoras constataram efeito negativo do PBF sobre as taxas de trabalho infantil, com efeito ainda maior nas áreas rurais, podendo ter relação direta com o aumento da frequência escolar encontrado. Com a diminuição do trabalho infantil, um aumento da participação das mães e dos pais em aproximadamente 3 pontos percentuais foi encontrado. As explicações para tal fenômeno se equiparam às explicações encontradas em outros trabalhos: com a diminuição do trabalho das crianças, a renda familiar se reduz e é necessária uma compensação, proporcionada pelo aumento do trabalho dos pais; outro motivo é que agora com as crianças sem trabalhar, elas passam mais tempo nas escolas e realizam mais tarefas domésticas, o que possibilita uma maior disposição de tempo para os pais trabalharem.

Apesar do encontrado por Tavares (2010) e por Ferro, Kassouf e Levison (2010), alguns trabalhos que também analisaram os efeitos do PBF encontraram resultados diferentes em relação ao trabalho infantil. Cardoso e Souza (2003) também encontraram um aumento significativo na frequência escolar, no entanto a diminuição do trabalho infantil não apresentou resultados significativos, que pode ser explicado pelo pequeno valor do benefício, tornando improvável as famílias renunciarem da renda proveniente das crianças.

Posteriormente, Pires (2013) analisou o Bolsa Família com dados da PNAD de 2006, e foram encontrados resultados não significativos da transferência de renda sobre o trabalho infantil. Assim como foi argumentado por Cardoso e Souza (2003), o principal motivo destacado foi o pequeno valor monetário do benefício do programa, levando a uma continuação da necessidade das famílias da renda proporcionada pelo trabalho infantil.

Cardoso e Souza (2003) sugerem que a transferência de renda muda o tempo de alocação da criança entre trabalho e escola; reduz a incidência de crianças que só trabalham e de crianças que não trabalham e nem estudam; e aumenta a incidência de crianças que só estudam e de crianças que estudam e trabalham; não apresentando redução geral do trabalho infantil.

Em 2013 foi evidenciada uma ausência de impactos significativos do programa Bolsa Família sobre o trabalho de crianças de 5 a 15 anos e sobre as horas por elas trabalhadas, tanto com dados coletados de 2009 quanto de 2011 da PNAD. Entretanto, através de modelos logit, foram encontrados impactos significativos e negativos do valor do benefício proporcionado pela transferência do PBF sobre as mesmas variáveis, trabalho infantil e 
horas trabalhadas. Ou seja, quanto maior for o crescimento da renda da transferência, menor será a probabilidade de a criança com domicílio urbano trabalhar; e o mesmo ocorre com relação às horas trabalhadas, tanto para crianças em domicílio urbano quanto rural (NASCIMENTO, 2013).

Assim como Nascimento (2013), Cacciamali, Tatei e Batista (2010) encontraram impactos estatisticamente significativos do PBF sobre as taxas de frequência escolar, mas não reduz o trabalho infantil. O estudo mostra que mesmo não sendo o foco do programa, o trabalho infantil caracteriza-se como um fenômeno intrínseco às famílias com baixas rendas.

É possível perceber através dos trabalhos analisados que existe uma divergência entre a conclusão dos efeitos do Bolsa Família sobre as taxas de trabalho infantil, e é por esse motivo que este artigo também se propõe a analisar o assunto em questão. Apesar dessa divergência, todos os trabalhos se assemelham na conclusão de que o programa afeta positivamente as taxas de frequência escolar.

\section{VARIÁVEIS UTILIZADAS E MÉTODO DE ANÁLISE}

Quadro 1 - Efeito Esperado das Variáveis Explicativas sobre as Variáveis Dependentes

\begin{tabular}{l|c|c|c|c|c}
\hline $\begin{array}{c}\text { Variáveis } \\
\text { Explicativas }\end{array}$ & $\begin{array}{c}\text { Óbitos } \\
\text { evitáveis }\end{array}$ & $\begin{array}{c}\text { Proporção } \\
\text { de pobres }\end{array}$ & $\begin{array}{c}\text { Renda } \\
\text { domiciliar }\end{array}$ & $\begin{array}{c}\text { Taxa de } \\
\text { desemprego }\end{array}$ & $\begin{array}{c}\text { Taxa de } \\
\text { trabalho } \\
\text { infantil }\end{array}$ \\
\hline No benefícios & $(-)$ & $(-)$ & $(+)$ & $(-)$ & $(-)$ \\
Fundamental completo & $(-)$ & $(-)$ & $(+)$ & $(-)$ & $(-)$ \\
Índice de Gini & $(+)$ & $(+)$ & $(-)$ & $(+)$ & $(+)$ \\
PIB per capita & $(-)$ & $(-)$ & $(+)$ & $(-)$ & $(-)$ \\
Taxa de analfabetismo & $(+)$ & $(+)$ & $(-)$ & $(+)$ & $(+)$ \\
Valor bruto agrícola & $(+/-)$ & $(+/-)$ & $(+/-)$ & $(+/-)$ & $(+/-)$ \\
Valor bruto indústria & $(+/-)$ & $(+/-)$ & $(+/-)$ & $(+/-)$ & $(+/-)$ \\
\hline
\end{tabular}

Nota-se no Quadro 1 que os efeitos esperados dos valores brutos da agricultura e da indústria sobre as variáveis dependentes podem ser ambíguos. Por um lado, quanto maior o valor bruto gerado no município maior sua riqueza $e$, consequentemente, melhores indicadores (menos mortes e pobreza e mais emprego). Por outro lado, pode ser que um maior valor bruto da agricultura em relação ao valor bruto da indústria capte o efeito de piores condições de vida, sob a hipótese de que a maior parcela do emprego agrícola é composta por trabalhadores menos qualificados e de menores salários, ou que o trabalho é altamente mecanizado e não absorve os trabalhadores menos qualificados.

\section{RESULTADOS E DISCUSSÃO}

Primeiramente é apresentada a decomposição da variância realizada para o modelo de dados em painel deste trabalho, considerado um painel curto, com número de municípios maior do que o de períodos de tempo $(T<N)$, especificada na Tabela 1.

Como pode se perceber na Tabela 1 , os municípios brasileiros são invariantes ao longo do tempo, apresentando variação within igual a zero. Já em relação ao ano, a variável 
referente ao tempo é variante entre municípios, apresentando variação between diferente de zero, se tratando de um painel desbalanceado.

Através da decomposição da variância explicitada na Tabela 1, nota-se que todas as variáveis utilizadas no modelo, tanto explicativas como dependentes, apresentam uma variação between maior que a variação within, ou seja, uma maior variação entre municípios do que ao longo do tempo. É possível constatar que os resultados obtidos com essa decomposição permitem um maior embasamento para a utilização dos modelos de dados em painel e a aplicação de vários estimadores.

0 primeiro teste realizado foi o teste de Breusch-Pagan, que analisa se o melhor modelo a ser utilizado é o modelo pooling ou o modelo de efeitos aleatórios. Sua hipótese nula diz que o modelo pooling seria melhor do que o modelo de efeitos aleatórios. Em todas as cinco variáveis dependentes deste trabalho, explicitadas anteriormente, a hipótese nula foi rejeitada, portanto rejeitou-se a hipótese de que o modelo pooling seria o mais adequado. Seguidamente, para testar os modelos de efeitos aleatórios e fixos, foi utilizado o teste de Hausman, no qual a hipótese nula considera o modelo de efeitos aleatórios melhor do que o modelo de efeitos fixos. Novamente, em todo o conjunto de variáveis dependentes, todas as hipóteses nulas foram rejeitadas, portanto descartou-se a hipótese de que o modelo de efeitos aleatórios seria o ideal. Dessa maneira, o modelo de efeitos fixos foi utilizado para cada uma das cinco variáveis dependentes.

Tabela 1 - Decomposição da Variância do Modelo

\begin{tabular}{|c|c|c|c|c|c|c|c|}
\hline Variáveis & & Mean & Std. Dev. & Min. & Max. & Obs & acões \\
\hline \multirow{3}{*}{$\begin{array}{l}\text { Proporção de } \\
\text { Pobres }\end{array}$} & Overall & 54.56 & 23.45 & 2.15 & 98.48 & $\mathrm{~N}$ & 11072 \\
\hline & Between & & 21.15 & 3.05 & 93.96 & $\mathrm{~N}$ & 5565 \\
\hline & Within & & 10.18 & 26.78 & 82.33 & T-bar & 1.99 \\
\hline \multirow{3}{*}{$\begin{array}{c}\text { Renda } \\
\text { domiciliar }\end{array}$} & Overall & 410.57 & 232.18 & 42.81 & 3468.2 & $\mathrm{~N}$ & 11072 \\
\hline & Between & & 214.31 & 80.18 & 2298.03 & $\mathrm{~N}$ & 5565 \\
\hline & Within & & 90.20 & -759.60 & 1580.73 & T-bar & 1.99 \\
\hline \multirow{3}{*}{$\begin{array}{c}\text { Taxa de } \\
\text { desemprego }\end{array}$} & Overall & 8.32 & 5.32 & 0 & 58.04 & $\mathrm{~N}$ & 11072 \\
\hline & Between & & 4.27 & 0 & 39.03 & $\mathrm{~N}$ & 5565 \\
\hline & Within & & 3.19 & -12.83 & 29.48 & T-bar & 1.99 \\
\hline \multirow{3}{*}{$\begin{array}{c}\text { Taxa de } \\
\text { trabalho } \\
\text { infantil }\end{array}$} & Overall & 15.30 & 9.37 & 0 & 97.58 & $\mathrm{~N}$ & 11072 \\
\hline & Between & & 8.10 & 1.16 & 72.83 & $\mathrm{~N}$ & 5565 \\
\hline & Within & & 4.81 & -15.89 & 46.50 & T-bar & 1.99 \\
\hline \multirow{3}{*}{$\begin{array}{l}\text { Óbitos } \\
\text { evitáveis }\end{array}$} & Overall & 0.34 & 0.31 & 0 & 4.29 & $\mathrm{~N}$ & 11072 \\
\hline & Between & & 0.23 & 0 & 2.45 & $\mathrm{~N}$ & 5565 \\
\hline & Within & & 0.22 & -1.56 & 2.25 & T-bar & 1.99 \\
\hline \multirow{3}{*}{$\begin{array}{l}\text { Número de } \\
\text { benefícios }\end{array}$} & Overall & 1751.48 & 5585.92 & 1 & 196699 & $\mathrm{~N}$ & 11043 \\
\hline & Between & & 5175.09 & 6.5 & 166064 & $\mathrm{~N}$ & 5564 \\
\hline & Within & & 2058.66 & -62546.02 & 66048.98 & T-bar & 1.99 \\
\hline \multirow{3}{*}{$\begin{array}{c}\text { Fundamental } \\
\text { completo }\end{array}$} & Overall & 54.07 & 19.98 & 0.94 & 97.45 & $\mathrm{~N}$ & 11071 \\
\hline & Between & & 14.42 & 11.55 & 91.75 & $\mathrm{~N}$ & 5565 \\
\hline & Within & & 13.87 & 20.03 & 88.10 & T-bar & 1.99 \\
\hline \multirow{3}{*}{ Índice de Gini } & Overall & 0.53 & 0.07 & 0.28 & 0.88 & $\mathrm{~N}$ & 11072 \\
\hline & Between & & 0.06 & 0.30 & 0.79 & $\mathrm{~N}$ & 5565 \\
\hline & Within & & 0.04 & 0.34 & 0.72 & T-bar & 1.99 \\
\hline \multirow{3}{*}{ PIB per capita } & Overall & 8439.11 & 11417.48 & 641.17 & 296786.3 & $\mathrm{~N}$ & 11072 \\
\hline & Between & & 9132.59 & 1534.02 & 210243.7 & $\mathrm{~N}$ & 5565 \\
\hline & Within & & 6956.67 & -126262.7 & 143140.9 & T-bar & 1.99 \\
\hline \multirow{3}{*}{$\begin{array}{c}\text { Taxa de } \\
\text { analfabetismo }\end{array}$} & Overall & 18.29 & 11.31 & 0.8 & 62.6 & $\mathrm{~N}$ & 11072 \\
\hline & Between & & 10.88 & 0.95 & 51.8 & $\mathrm{~N}$ & 5565 \\
\hline & Within & & 3.07 & -0.06 & 36.64 & T-bar & 1.99 \\
\hline
\end{tabular}




\begin{tabular}{cccccccc}
\hline & & & & & & & \\
Valor Bruto & Overall & 20.63 & 35.49 & 0 & 624.13 & $\mathrm{~N}$ & 11072 \\
Agricultura & Between & & 29.84 & 0 & 384.07 & $\mathrm{~N}$ & 5565 \\
& Within & & 19.30 & -244.64 & 285.90 & T-bar & 1.99 \\
\hline Valor Bruto & Overall & 107.40 & 983.99 & 0.1051 & 74122.19 & $\mathrm{~N}$ & 11072 \\
Indústria & Between & & 902.01 & 0.4276 & 54740.33 & $\mathrm{~N}$ & 5565 \\
& Within & & 387.95 & -19274.45 & 19489.26 & T-bar & 1.99 \\
\hline
\end{tabular}

Fonte: Tabela elaborada pelo autor

Como todas as variáveis dependentes utilizaram o modelo de efeitos fixos, a Tabela 2 uniu todos esses efeitos de cada uma das variáveis explicativas sobre o conjunto das variáveis dependentes.

Tabela 2 - Efeitos Fixos das Variáveis Explicativas Sobre Cada Variável Dependente

\begin{tabular}{|c|c|c|c|c|c|}
\hline $\begin{array}{l}\text { Variáveis } \\
\text { Explicativas }\end{array}$ & Óbitos evitáveis & $\begin{array}{l}\text { Proporção de } \\
\text { pobres }\end{array}$ & $\begin{array}{c}\text { Renda } \\
\text { domiciliar }\end{array}$ & $\begin{array}{c}\text { Taxa de } \\
\text { desemprego }\end{array}$ & $\begin{array}{c}\text { Taxa de } \\
\text { trabalho infanti }\end{array}$ \\
\hline $\begin{array}{c}\text { No benefícios } \\
(100)\end{array}$ & $-0,0005185^{*}$ & $-0,0002299$ & $0,09643 *$ & $-0,01722 *$ & 0,006081 \\
\hline $\begin{array}{l}\text { Fundamental } \\
\text { completo }\end{array}$ & $-0,004320 *$ & $-0,448808^{*}$ & $4,203384 *$ & $-0,043690 *$ & $-0,141179 *$ \\
\hline Índice de Gini & $0,439511 *$ & $51,157578 *$ & $296,06458 *$ & $16,94111^{*}$ & 0,154216 \\
\hline $\begin{array}{l}\text { PIB per capita } \\
\text { (100) }\end{array}$ & $-0,00005536$ & $-0,002405^{*}$ & $0,3674 *$ & 0,008397* & $-0,004143 *$ \\
\hline $\begin{array}{c}\text { Taxa de } \\
\text { analfabetismo }\end{array}$ & 0,010065* & $0,12376075^{*}$ & $1,485526 *$ & 0,042492* & 0,036000 \\
\hline $\begin{array}{l}\text { Valor bruto } \\
\text { agrícola }\end{array}$ & 0,00001138 & $-0,0279795^{*}$ & $0,378662 *$ & $-0,013216^{*}$ & $-0,006354$ \\
\hline $\begin{array}{l}\text { Valor bruto } \\
\text { indústria }\end{array}$ & $-0,000004879$ & $0,0006166^{*}$ & 0,003591 & $-0,0003557^{*}$ & 0,00003922 \\
\hline
\end{tabular}

* estatisticamente significativo a $5 \%$

Fonte: tabela elaborada pelo autor

Óbitos evitáveis de crianças menores do que cinco anos

De acordo com a Tabela 2, as únicas variáveis explicativas que não apresentam impactos estatisticamente significativos (a $5 \%$ ) sobre o número de óbitos evitáveis de crianças menores de cinco anos por mil habitantes são as variáveis que representam o PIB per capita do município, o valor adicionado brutos da agricultura e o valor adicionado bruto da indústria.

O produto interno bruto per capita de uma cidade, portanto, não apresenta influência sobre os óbitos evitáveis de crianças, e isso pode ser explicado pelo fato de que essa renda não necessariamente possui um direcionamento para as áreas de saúde e infraestrutura pública, as quais poderiam refletir numa redução da mortalidade infantil. Como os valores adicionados brutos da agricultura e da indústria são parcelas do PIB, o fato de também não haver impacto dessas variáveis é coerente com o fato do produto também não apresentar relação.

Já em relação as variáveis explicativas que se relacionam com a educação, ambas apresentam coeficientes estatisticamente significativos a $5 \%$ sobre os óbitos evitáveis de crianças menores do que cinco anos. $\mathrm{O}$ aumento da taxa de analfabetismo do município 
eleva o número de óbitos evitáveis, assim como o aumento da proporção de pessoas entre 18 e 24 anos que possuem pelo menos o ensino fundamental completo reduz a mortalidade infantil. Isso porque em uma sociedade melhor instruída e com um nível maior de conhecimento, cuidados com a saúde infantil são mais conhecidos e colocados em prática.

O resultado mais expressivo apresentado na Tabela 2 é o efeito do índice de Gini. Deve ser lembrado que esse índice varia de 0 a 1 , sendo que 1 representaria total desigualdade social. Portanto, um aumento de 0,1 ponto no índice de Gini de um município resulta num aumento de 0,044 dos óbitos evitáveis por mil habitantes, aproximadamente. Essa relação positiva e estatisticamente significativa entre Gini e mortalidade infantil é entendida porque a desigualdade social tem relação com a precariedade de infraestrutura pública (principalmente saneamento básico e habitação) e saúde. Em um município com elevada desigualdade social, entende-se que uma parte representativa da população não teria acesso a uma saúde de qualidade e a condições apropriadas de higiene. Esses fatores ajudam a explicar um número de óbitos evitáveis de crianças menor em locais com uma menor desigualdade, onde o acesso a melhores condições de saúde de qualidade é, de certa forma, mais abrangente.

Analisando a variável de interesse deste estudo, o número de benefícios por município, observa-se efeito estatisticamente significativo e negativo sobre o número de óbitos evitáveis por mil habitantes. 0 aumento, por exemplo, de 100 benefícios entre mil habitantes de um município reduz em 0,00052 os óbitos evitáveis, ou seja, apesar de significativo, o impacto do programa parece ser muito pequeno.

Comparando os resultados obtidos com outros trabalhos, encontra-se uma divergência em relação a estudo anterior. Essa discordância pode ser consequência da utilização de variáveis diferentes nos modelos elaborados, uma vez que este trabalho utilizou como proxy da mortalidade infantil os óbitos evitáveis de crianças, enquanto Camelo, Tavares e Saiani (2009) utilizam a taxa de mortalidade infantil e encontram coeficientes não significativos estatisticamente. Portanto, é possível que o Bolsa Família teria impacto estatisticamente significativo sobre as mortes que poderiam ter sido evitadas, mas não teria efeito estatisticamente significativo sobre a taxa de mortalidade que leva em consideração todos os óbitos infantis, sem diferenciação entre evitáveis ou não.

Esses resultados podem ter relação com o fato do Bolsa Família estipular algumas condicionalidades que ajudem a prevenir situações críticas de saúde em crianças, como é o caso da obrigação de exames de pré-natal e de acompanhamento pediátrico para crianças até seis anos, por exemplo. Entretanto, como já explicitado, esse impacto é relativamente muito pequeno. Esse efeito também pode ter relação com as reduções da taxa de mortalidade brasileira nos últimos anos; para que essas contrações tenham continuidade seria necessário a utilização de políticas mais focalizadas neste ponto (CAMELO; TAVARES; SAIANI, 2009).

\section{Proporção de pessoas em domicílios com renda inferior a meio salário mínimo}

Ao analisar os impactos das variáveis explicativas sobre a proporção de indivíduos que vivem em domicílios com renda inferior a meio salário mínimo, nota-se que o índice de Gini é a variável com maior efeito. Uma elevação de 0,1 no índice aumenta a proporção de pobres em 5,1 pontos percentuais, um impacto considerado elevado (Tabela 2). Esse é um resultado esperado, afinal o aumento da proporção de pobres apresenta forte relação com o aumento da desigualdade social e econômica daquele município. 
Em relação ao PIB per capita do município, nota-se na Tabela 2 um efeito estatisticamente significativo e negativo sobre a proporção de pobres. Entretanto, é um impacto pequeno, um aumento de $\mathrm{R} \$ 100,00$ no PIB per capita do município reduz em 0,0024 a variável dependente em questão. O PIB per capita de um município, portanto, não apresenta relação positiva com a proporção de pobreza. Como os resultados encontrados são muito pequenos, pode-se concluir que esse aumento de renda não é igualitário, ou seja, essa elevação do PIB provavelmente possui reflexo maior no aumento da renda das classes mais altas do que das mais baixas.

Sobre à relação da educação com a proporção de pobres, é possível perceber que ambas as variáveis explicativas sobre esse ponto são estatisticamente significativas. Um aumento da proporção de jovens com pelo menos o segundo ciclo do ensino fundamental completo está relacionado à uma proporção de pobres 0,45 ponto percentual menor; já o aumento da taxa de analfabetismo corresponde a um aumento de 0,12 nessa proporção. Esses resultados apresentam relação direta com a ideia de que quanto maior o nível de ensino, maior a qualificação profissional do indivíduo, maiores salários, e, portanto, uma menor proporção de pobreza.

Os resultados obtidos para a variável de interesse - número de benefícios do PBF por município - apontam para um efeito estatisticamente não significativo (a um nível de $5 \%$ ) sobre a proporção de pobres num dado município, enquanto a literatura aponta para outras conclusões.

Soares et. al. (2010), por exemplo, encontraram resultados estatisticamente significativos e expressivos sobre a redução de pobreza relacionada à transferência de renda condicionada pelo Bolsa Família, assim como Soares e Satyro (2009). Entretanto, alguns pontos podem explicar essas divergências. Neste trabalho, para a medição de pobres, foi utilizada a proporção de pessoas que vivem em domicílios com renda inferior a meio salário mínimo, o que representa um valor acima de $\mathrm{R} \$ 400,00$. Já nos estudos de Soares e Satyro (2009), a linha de pobreza é considerada abaixo de $R \$ 120,00$, e de Soares et al. (2010), abaixo de $\mathrm{R} \$ 100,00$. Essa diferença é um fator relevante que explica a desarmonia de resultados, uma vez que o impacto do PBF sobre a pobreza considerando valores abaixo de $\mathrm{R} \$ 100,00$ é, consequentemente, maior do que para valores abaixo de $\mathrm{R} \$ 400,00$.

\section{Renda média domiciliar per capita}

Observando os resultados na Tabela 2 sobre a renda média domiciliar per capita, percebe-se que novamente o maior impacto é o do índice de Gini. Um aumento de 0,1 no índice resulta num aumento de aproximadamente $\mathrm{R} \$ 29$ na renda domiciliar. Nota-se que a variável explicativa que vem apresentando maior magnitude é o índice de Gini, e por mais que um aumento de 0,1 seja considerado um aumento expressivo de desigualdade, se considerarmos um aumento de 0,01 ainda representaria um impacto elevado na renda domiciliar per capita média, de quase $\mathrm{R} \$ 3,00$.

O PIB per capita apresenta também impacto estatisticamente significativo e positivo sobre a renda domiciliar. Entretanto, é um efeito considerado pequeno, pois um aumento de $\mathrm{R} \$ 100,00$ do PIB per capita resulta em um aumento de $\mathrm{R} \$ 0,37$ da renda média domiciliar per capita. O PIB representa o produto interno bruto da cidade, enquanto a renda domiciliar é a média entre as rendas domiciliares per capita do município. Um aumento dos recursos monetários de um município não necessariamente impacta na mesma proporção a renda das famílias. 
Na Tabela 2, nota-se um expressivo impacto também da proporção de jovens com pelo menos o ensino fundamental completo. Um aumento dessa proporção resulta num aumento de $\mathrm{R} \$ 4,20$ na renda média domiciliar per capita do município. A relação entre educação e renda é bem estabelecida na teoria do capital humano (SCHULTZ, 1963; BECKER, 1962; MINCER, 1958). Um aumento do nível educacional do indivíduo resulta num aumento da sua qualificação para o mercado de trabalho, e, portanto, maior produtividade e maiores salários. Entretanto, ao contrário do esperado, a taxa de analfabetismo tem impacto estatisticamente significativo e positivo sobre a renda domiciliar. Era esperado que com uma taxa de analfabetismo menor, a renda média seria maior, uma vez que se eleva o nível educacional da população.

No tocante a variável de interesse desta pesquisa, o efeito é estatisticamente significativo e positivo. $\mathrm{O}$ aumento de, por exemplo, cem benefícios no município eleva a renda domiciliar média per capita em $\mathrm{R} \$ 0,096$. Um resultado que, apesar de significativo, é pequeno.

Esse resultado encontrado tem relação com o baixo valor da transferência de renda condicionada que o programa promove. Os valores não seriam relevantes para aumentar a renda média domiciliar significativamente. Entretanto, apresenta relação estatisticamente significativa, como aponta a literatura pesquisada.

Tanto Soares et al. (2010), quanto Soares e Satyro (2009), encontraram resultados estatisticamente significativos do Bolsa Família sobre a redução da pobreza e da desigualdade no Brasil. Não foi tratada a relação com a renda, mas entende-se que uma diminuição da pobreza estaria relacionada com uma elevação da renda média das famílias. Da mesma forma, a redução do índice de Gini encontrada pelos autores citados também representaria uma elevação da renda média das famílias mais pobres, apesar de poder também implicar numa redução da renda média das classes mais altas.

Assim como Soares et al. (2010) e Soares e Satyro (2009), Tavares et al. (2008) também encontraram efeitos estatisticamente significativos do Programa Bolsa Família sobre a redução da pobreza e da extrema pobreza, o que resultaria num aumento da renda média das famílias mais pobres.

Taxa de desemprego da população com 16 anos ou mais

Analisa-se agora a variável dependente foco deste artigo, uma vez que a principal proposta desta pesquisa é verificar os impactos do Bolsa Família sobre as taxas de emprego e de desemprego nos municípios brasileiros.

No tocante às variáveis explicativas utilizadas como proxy de educação, nota-se que os efeitos são estatisticamente significativos e têm o sinal esperado. Um aumento da taxa de analfabetismo aumenta em 0,04 a taxa de desemprego, enquanto um aumento na proporção de jovens com pelo menos o segundo ciclo do ensino fundamental completo reduz essa taxa em 0,04.

Percebe-se que, diferentemente do impacto em outras variáveis dependentes, a taxa de analfabetismo e a proporção de indivíduos entre 18 e 24 anos com ensino fundamental completo possuem um efeito de mesma magnitude sobre a taxa de desemprego nos municípios brasileiros. Uma possível explicação é que a diferenciação de nível educacional que caracteriza essas variáveis explicativas não influencia na empregabilidade dos indivíduos. Uma maior qualificação profissional implica em salários mais elevados, mas pode ser que o efeito sobre a participação não seja captado da mesma forma, posto que existe 
uma grande variabilidade de ocupações e empregos disponíveis, de diferentes níveis de qualificação profissional requeridos.

O PIB per capita apresenta efeito estatisticamente significativo e positivo sobre a taxa de desemprego. Contudo, é um resultado pouco expressivo, já que o aumento do PIB per capita em $\mathrm{R} \$ 100,00$ representa um aumento de 0,0084 na taxa de desemprego.

Essa relação pode ser explicada pela mesma linha de raciocínio que foi usada para explicar a relação do PIB com os óbitos evitáveis. Um aumento do PIB do município não necessariamente resulta em melhorias diretas para a população, já que seus recursos têm como destino gastos e investimentos em diversas áreas da economia, não sendo possível saber ao certo por este modelo qual destino está ligado ao aumento do PIB per capita de um município.

Os valores brutos adicionados da agricultura e da indústria apresentam resultados estatisticamente significativos e negativos. Entretanto, nota-se uma magnitude maior do setor agrícola em comparação ao industrial. Um aumento de um milhão de reais do valor adicionado bruto da agricultura reduz em 0,01 as taxas de desemprego, enquanto o da indústria reduz a taxa em 0,0003.

Essa maior representatividade da agricultura pode ser explicada pelo fato de que um município mais focado e voltado para o setor industrial apresenta maior mecanização e modernização do que o setor agrícola, refletindo numa redução da necessidade de mão de obra (menos qualificada) e, consequentemente, numa maior taxa de desemprego.

Analisando os efeitos do índice de Gini, observa-se na Tabela 2 novamente um resultado expressivo. $\mathrm{O}$ índice apresenta impacto estatisticamente significativo e positivo sobre a taxa de desemprego da população com 16 anos ou mais. Um aumento de 0,1 do índice representa uma elevação em 1,7 da taxa de desemprego do município.

Para a variável de interesse foi encontrado impacto estatisticamente significativo e negativo sobre a taxa de desemprego, dado um nível de confiança de $5 \%$. É possível constatar pela Tabela 2 que um aumento de cem benefícios do Bolsa Família num município reduz em 0,02 a taxa de desemprego.

O resultado encontrado pode ser comparado com diversos trabalhos revisados com efeitos semelhantes. Entretanto, um desses estudos encontrou alguns efeitos diferentes dos que foram tratados aqui. Apesar de encontrar impactos significativos na participação de homens no mercado de trabalho, Foguel e Barros (2010) evidenciaram esses impactos como muito pequenos, além de encontrar efeitos estatisticamente não significativos na participação das mulheres. Isso pode ser explicado pela divergência de períodos. O trabalho citado utilizou dados da PNAD de 2001 a 2005, enquanto que para este trabalho foram utilizados dados de 2000 e de 2010.

Já no caso de trabalhos com resultados semelhantes ao deste estudo, pode ser citado o caso da pesquisa de Soares, Ribas e Osório (2010), que encontraram aumento da participação de homens e mulheres beneficiários no mercado de trabalho em relação a não beneficiários. Esses resultados encontrados sobre as taxas de desemprego podem ter relação com uma visão teórica defendida por Soares e Satyro (2009), a qual defende que esse benefício condicionado serviria para cobrir os custos de procurar um novo emprego.

Outra explicação para o impacto positivo nas taxas de emprego encontrados neste estudo baseia-se no aumento de frequência escolar e redução do trabalho infantil resultantes do Bolsa Família. Tavares (2010) e Ferro, Kassouf e Levison (2010) encontraram um aumento da participação de trabalho dos pais relacionado a uma redução do trabalho infantil, por conta do aumento da frequência escolar. Quando os pais se encontram com maior tempo disponível, dado que seus filhos estariam passando mais tempo nas escolas, 
ou perdem uma parte da sua renda que era proveniente do trabalho das crianças de seus domicílios, os adultos da casa aumentam sua procura por emprego ou suas horas trabalhadas.

Todavia, este trabalho não encontrou impactos estatisticamente significativos do PBF sobre as taxas de trabalho infantil, conforme será tratado adiante. Esse é o caso também dos trabalhos de Cardoso e Souza (2003) e Cacciamali, Tatei e Batista (2010), que encontram aumento de participação dos pais no mercado de trabalho, no caso de Cardoso e Souza (2003), mas não evidenciaram uma redução do trabalho infantil, para ambos os trabalhos.

Uma outra questão interessante de ser tratada sobre o assunto é um ponto trazido por Tavares (2010) sobre a relação negativa entre o PBF e as taxas de desemprego. Essa questão é o chamado "efeito estigma". "Efeito estigma" se caracteriza, basicamente, pelo aumento da procura de emprego dos beneficiários devido a uma discriminação sofrida por causa do preconceito relacionado a transferências de renda. Os indivíduos que recebem esse benefício, ao se sentirem marginalizados, tendem a aumentar seu esforço para conseguir empregos, com o objetivo de reduzir, ou ainda cortar, sua dependência do programa.

Apesar dos resultados encontrados, é importante ressaltar uma limitação deste trabalho. O aumento do número de benefícios por município aponta para uma redução da taxa de desemprego. Contudo, sabe-se que a taxa de desemprego é a relação entre o número de pessoas desocupadas e o número de pessoas economicamente ativas. Logo, a redução da taxa de desemprego pode ser decorrente de uma redução do número de pessoas desocupadas, ou da redução da população economicamente ativa. Além disso, a agregação necessária para a análise pode influenciar os resultados, uma vez que teoricamente as decisões ocupacionais se dão a nível de indivíduo.

\section{Proporção de indivíduos entre 10 e 15 anos ocupados}

O índice de Gini foi a variável explicativa que mais apresentou impacto nas variáveis dependentes anteriores. Entretanto, sobre a variável dependente que representa o trabalho infantil foi encontrado impacto estatisticamente não significativo do índice. Isso pode ser explicado talvez pelo fato de que um aumento no índice de Gini não necessariamente representa uma redução da renda das classes mais baixas, mas pode significar também um aumento da renda das classes mais altas. Portanto, se esse aumento de desigualdade estiver relacionado a uma maior concentração de renda, e não a uma elevação da condição de pobreza de uma parte da população, o trabalho infantil realmente não apresentaria relação com a taxa de Gini.

O PIB per capita, entretanto, apresenta efeito estatisticamente significativo, como aponta a Tabela 2. Um aumento em $\mathrm{R} \$ 100,00$ do produto per capita do município resulta numa redução de 0,004 da taxa de trabalho infantil. Esse efeito tem relação direta com o efeito do PIB per capita sobre a taxa de desemprego. Do mesmo jeito que o aumento do produto interno municipal aumenta as taxas de desemprego, ele também reduz o trabalho infantil. Seria possível concluir, então, que o aumento do PIB influencia negativamente as taxas de emprego, independente se a taxa de emprego é da população adulta ou infantil.

Já em relação aos valores adicionados brutos da agricultura e da indústria, nenhum apresenta efeito estatisticamente significativo, ao nível de confiança de $5 \%$, sobre as taxas de ocupação de crianças entre 10 e 15 anos. Pode se concluir que um município que tenha 
seu produto composto em maioria pela agricultura, ou pela indústria, não influencia no fato de aumento ou redução do trabalho infantil.

Sobre as variáveis explicativas representativas da educação, impactos divergentes são encontrados. Enquanto a proporção de jovens com pelo menos o segundo ciclo do fundamental completo resulta numa redução de 0,14 na taxa de trabalho infantil, a taxa de analfabetismo não possui impacto estatisticamente significativo. Isso pode ser explicado se o analfabetismo não influenciar tanto, por exemplo, a conquista de emprego. Diferentemente do número de jovens com ensino fundamental, uma vez que por representar um maior grau de educação, pode resultar em empregos e remunerações melhores, o que dispensaria a necessidade de os jovens entre 10 e 15 anos precisarem completar a renda domiciliar.

$\mathrm{Na}$ Tabela 2, nota-se que o número de benefícios não apresentou impacto estatisticamente significativo sobre o trabalho infantil, assim como o encontrado pela maioria dos trabalhos revisados.

Entretanto, o trabalho de Ferro, Kassouf e Levison (2010) evidenciou impactos significativos do Bolsa Família sobre a redução do trabalho infantil, impulsionados pelo aumento da frequência escolar. Uma possível resposta para essa divergência de resultados encontrados é o fato de o trabalho citado utilizar dados do Bolsa Escola para o estudo, enquanto esta pesquisa utilizou o Bolsa Família.

Apesar disso, a maioria dos trabalhos revisados apresentaram impactos estatisticamente não significativos do programa sobre as taxas de trabalho infantil. Mesmo encontrando valores que evidenciem o aumento da frequência escolar impulsionado pelo PBF, Cardoso e Souza (2003), Nascimento (2013) e Cacciamali, Tatei e Batista (2010) não encontraram efeitos estatisticamente significativos sobre o trabalho infantil.

Cardoso e Souza (2003) defendem que o aumento da frequência escolar reduz a incidência de crianças que só trabalham e de crianças que não trabalham e nem estudam, mas também aumenta a incidência de crianças que só estudam e de crianças que estudam e trabalham; não apresentando uma redução geral das taxas de trabalho infantil.

Isso também ainda pode ser justificado pelo baixo valor dos benefícios proporcionados pelo programa, não descartando a necessidade de renda advinda das crianças do domicílio, ponto o qual teria sido defendido por Cardoso e Souza (2003) e por Pires (2013). Esse argumento encontra embasamento também pelos dados expostos por Nascimento (2013), uma vez que apesar de relatar impactos não significativos do PBF sobre o trabalho infantil, foram encontrados impactos significativos em relação ao valor do benefício. Um aumento do valor do benefício transferido pelo programa, segundos resultados obtidos pela autora, resultaria numa menor probabilidade de a criança urbana trabalhar, e no caso de horas trabalhadas, a redução seria tanto para crianças do meio urbano quanto do meio rural.

\section{CONSIDERAÇÕES FINAIS}

Este trabalho teve como objetivo principal analisar os impactos do Bolsa Família sobre as taxas de emprego nos municípios brasileiros. Como metodologia foi adotado o modelo de dados em painel e criaram-se cinco regressões para compreender os efeitos do PBF não somente sobre as taxas de desemprego, mas também sobre outros aspectos sociais e econômicos dos municípios nacionais, para se ter uma melhor noção de sua abrangência. 
Foi constatado, neste artigo, que o Bolsa Família tem efeitos estatisticamente significativos sobre a redução das taxas de desemprego nos municípios, apesar de representar um pequeno impacto. É importante ressaltar que este trabalho utilizou dados agregados por município, enquanto que as decisões de trabalho são, em geral, individuais, e isso pode implicar numa magnitude dos coeficientes menor do que esperada. Outro ponto é que as variáveis de riqueza e oportunidades, como por exemplo PIB e valor agregado, nem sempre são de fácil variação via políticas públicas locais, como o PBF, que possui cotas para os municípios.

O índice de Gini foi a variável explicativa que apresentou impactos mais expressivos sobre as variáveis dependentes analisadas, inclusive sobre a taxa de desemprego, portanto seria válido uma investigação sobre a relação entre o programa, a desigualdade de renda e as taxas de desemprego. um maior alcance do PBF seria um dos primeiros pontos que poderiam fortalecer esses resultados, já que alguns lugares de difícil acesso apresentam menores chances de participar do programa. Assistências do programa para essas áreas são de extrema importância no que se diz respeito a erradicação de pobreza e redução da desigualdade.

Valores maiores de benefício seriam também de considerável relevância para a continuidade do programa. Uma das principais razões para os pequenos impactos do PBF são os seus pequenos valores transferidos. Um aumento desses valores resultaria em maiores impactos sobre a redução da desigualdade, ocasionando menores taxas de desemprego, relação a qual foi evidenciada pelo estudo deste artigo.

O aumento do valor do benefício impactaria também as taxas de trabalho infantil, como constatado no trabalho de Nascimento (2013). Apesar de não terem sido encontrados efeitos estatisticamente significativos do PBF sobre o trabalho infantil, nem pela autora e nem por esta pesquisa, o aumento monetário dos benefícios implicaria numa redução da probabilidade de as crianças trabalharem, segundo a autora. E como já foi visto, a redução do trabalho infantil reflete positivamente nas taxas de emprego de adultos, uma vez que isso representa uma "perda de renda" para essas famílias.

Outro aspecto que tem influência sobre a redução de trabalho infantil é a frequência escolar. Todavia, apesar do aumento da frequência escolar, ainda se encontram períodos disponíveis para a criança trabalhar. Seria vantajoso, então, a criação de ações extraescolares, como as oferecidas pelo Programa de Erradicação do Trabalho Infantil (PEII), que reduziriam o tempo disponível dos jovens e investiria em atividades culturais, esportivas e profissionalizantes. Com essa redução do tempo disponível dos jovens, dada a condicionalidade de frequência mínima escolar já existente e as atividades extracurriculares sugeridas por este trabalho, os indivíduos responsáveis pelos domicílios se encontrariam em posição de aumentar a sua procura de emprego para repor essa "perda de renda".

Esse conceito de investimento em educação é extremamente importante para o programa. Foi constatado também impactos expressivos das variáveis explicativas relacionadas a educação sobre as taxas de emprego. Logo, as questões sugeridas pelo PETI ajudariam numa maior qualificação profissional futura das crianças para a procura de emprego, além de promover o seu afastamento do trabalho infantil. Afinal, o PBF precisa promover impactos de curto prazo na sociedade, mas são os efeitos de longo prazo que mais afetam positivamente uma economia.

Portanto, este artigo concluiu que o Bolsa Família possui impactos estatisticamente significativos sobre a redução das taxas de desemprego nos municípios brasileiros. Contudo, os impactos observados são pequenos, e isso pode ser decorrente da abrangência do programa - que possui cotas nos municípios - ou da dinâmica do mercado de trabalho. No 
entanto, não é possível excluir a possibilidade de que a agregação dos dados necessária para a realização das análises tenha certa influência sobre a magnitude dos coeficientes estimados.

\section{REFERÊNCIAS BIBLIOGRÁFICAS}

BAPSTITELLA, Juliana. Avaliação de Programas Sociais: Uma Análise do Impacto do Bolsa Família Sobre o Consumo de Alimentos. 2012. 101 f. Dissertação (Mestrado) - Curso de Economia, UFSCar, Sorocaba, 2012. Cap. 3.

BECKER, G. Investment in Human Capital: a theoretical analysis. Journal of Political Economy, v.70, n.5/2, p.9-49, 1962.

CACCIAMALI, Maria Cristina; TATEI, Fábio; BATISTA, Natália Ferreira. Impactos do Programa Bolsa Família Sobre o Trabalho Infantil e a Frequência Escolar. Revista de Economia Contemporânea, São Paulo, v. 14, n. 2, p.269-301, abr. 2010.

CAMELO, Rafael; TAVARES, Priscilla; SAIANI, Carlos. Alimentação, Nutrição e Saúde em Programas de Transferência de Renda: Evidências Para o Programa Bolsa Família. Revista Economia, Brasília, v. 10, n. 4, p.685-713, dez. 2009.

CAMERON, A. Colin; TRIVEDI, Pravin K. Microeconometrics Using Stata. College Section: Stata Press, 2009.

CAMPELLO, Tereza; NERI, Marcelo (Org.). Programa Bolsa Família: Uma década de inclusão e cidadania. Brasília: IPEA, 2013. 494 p.

CARDOSO, Eliana; SOUZA, André Portela. The Impact of Cash Transfers on Child Labor and School Attendance in Brazil. São Paulo: Departamento de Economia da Universidade de São Paulo, 2003.

DATASUS. Disponível em < http://www.datasus.gov.br >. Acesso em: 20/05/2018.

FÁVERO, Luiz Paulo et al. Métodos Quantitativos com Stata. Rio de Janeiro: Elsevier Editora Ltda., 2014. 248 p.

FERRO, Andrea; KASSOUF, Ana Lúcia; LEVISON, Deborah. The Impact of Conditional Cash Transfer Programs on Household Work Decisions in Brazil. Research in Labor Economics, v.31, p.193-218. 2010.

FOGUEL, Miguel Nathan; BARROS, Ricardo Paes. O Efeito dos Programas Condicionais de Transferências de Renda Sobre a Taxa de Participação no Brasil: Uma Análise com o Painel de Municípios da PNAD. In: ANPEC: XXXVI ENCONTRO NACIONAL DE ECONOMIA, 2008.

IPEA DATA. Dados Sociais, Programa Bolsa Família (PBF) número de benefícios. Disponível em < http://www.ipeadata.gov.br/Default.aspx > . Acesso em: 20/05/2018.

IPEA DATA. Dados Sociais, Programa Bolsa Família (PBF) valor total dos benefícios. Disponível em < http://www.ipeadata.gov.br/Default.aspx > . Acesso em: 20/05/2018.

MARQUES, Luiz David. Modelos Dinâmicos com Dados em Painel: Revisão de Literatura. Série Working Papers do Centro de Estudo Macroeconômicos e Previsão (CEMPRE) da Faculdade de Economia do Porto, Portugal, n 100, 2000. 
MINCER, J. Investment in human capital and personal income distribution. Journal of Political Economy. v.66, 1958. Disponível em http://

ideas.repec.org/a/ucp/jpolec/v66y1958p281.html.

MINISTÉRIO do DESENVOLVIMENTO SOCIAL (MDS). Dados Sociais, Programa Bolsa Família (PBF) número de benefícios. Disponível em <

http://www.ipeadata.gov.br/Default.aspx >. Acesso em: 20/05/2018.

MINISTÉRIO do DESENVOLVIMENTO SOCIAL (MDS). Dados Sociais, Programa Bolsa Família (PBF) valor total dos benefícios. Disponível em <

http://www.ipeadata.gov.br/Default.aspx >. Acesso em: 20/05/2018.

NASCIMENTO, Adriana Rosa do. Impacto do Programa Bolsa Família Sobre as

Decisões de Trabalho das Crianças:Uma Análise Utilizando os Microdados da PNAD. 2013. 128 f. Dissertação (Mestrado) - Curso de Economia, Universidade de São Paulo, Piracicaba, 2013.

PIRES, André. Afinal, para que servem as condicionalidades em educação do Programa Bolsa Família? Ensaio: avaliação e políticas públicas em educação, Rio de Janeiro, v. 21, n. 80, p. 513-532, 2013.

Portal da Transparência nos Recursos Públicos Federais. Disponível em: <http://transparencia.gov.br/>. Acesso em: 15 fev. 2016.

SATYRO, N.; SOARES, S. S. O Programa Bolsa Família: Desenho institucional, impactos e possibilidades futuras. Discussion Papers, n. 1424, Instituto de Pesquisa Econômica Aplicada - IPEA, 2009.

SCHULTZ, T. W. The Economic Value of Education. New York: Columbia University Press, 1963.

SIDRA - Sistema IBGE de Recuperação Automática. Disponível em:

<http://www.sidra.ibge.gov.br/>. Acesso em: 11 fev. 2016.

SOARES, Fabio Veras; RIBAS, Rafael Perez; OSÓRIO, Rafael Guerreiro. Evaluating the Impact of Brazil's Bolsa Família: Cash Transfer Programmes in Comparative Perspective. Evaluation Note, no 1, International Poverty Centre, Brasília, 2007.

SOARES, Sergei et al. Os Impactos do Benefício do Programa Bolsa Família Sobre a Desigualdade e a Pobreza. In: CASTRO, Jorge Abrahão de; MODESTO, Lúcia. Bolsa Família 2003-2010: Avanços e Desafios. Brasília: Ipea, 2010. p. 27-52.

TAVARES, Priscilla Albuquerque. Efeito do Programa Bolsa Família sobre a oferta de trabalho das mães. In: SEMINÁRIO SOBRE ECONOMIA MINEIRA - ECONOMIA, HISTÓRIA, DEMOGRAFIA E POLÍTICAS PÚBLICAS, 13. Anais... Diamantina, ago. 2008.

TAVARES, Priscilla Albuquerque; PAZELLO, Elaine Toldo; FERNANDES, Reynaldo; CAMELO, Rafael Souza. Uma avaliação do Programa Bolsa Família: focalização e impacto na distribuição de renda e pobreza. Ribeirão Preto [s.n.], 2008. Mimeografado.

TEIXEIRA, C. G. Análise do Impacto do Programa Bolsa Família na Oferta de Trabalho dos Homens e Mulheres. 2008, UNDP/IPC.

THE WORLD BANK. Disponível em: <http://data.worldbank.org/indicator/SI.POV.GINI>. Acesso em: 12 maio 2018. 